account of the current events of domestic and foreign policy, which affect the general trends in the functioning of the state. In conclusion, the author decides that the duality of the phenomenon of the Presidential Address to the Federal Assembly still allows us to single out the fundamental factor, which is the political side of the presidential message. Moreover, although the event is constitutionalized, the political influence is more important if it is contained in the message and have an impact on society and the state.

Keywords: Presidential Address to the Federal Assembly, Constitution, Federal Assembly, deputies of State Duma, senators of Russian Federation

КУКОНКОВ Павел Иванович - кандидат социологических наук, старший научный сотрудник Приволжского филиала ФНИСЦ РАН (603000, Россия, г. Нижний Новгород, Холодный пер., 4; kukonkov_pavel@rambler.ru)

УСТИНКИН Сергей Васильевич - доктор исторических наук, профессор; директор Приволжского филиала ФНИСЦ РАН (603000, Россия, г. Нижний Новгород, Холодный пер., 4); начальник международной междисциплинарной научно-исследовательской лаборатории изучения мировых и региональных социально-политических процессов; научный руководитель Высшей школы международных отношений и мировой политики Нижегородского государственного лингвистического университета им. Н.А. Добролюбова (603950, Россия, г. Нижний Новгород, ул. Минина, 31a; sv.ustinkin@ gmail.com)

МОРОЗОВА Наталья Михайловна - кандидат политических наук, доцент кафедры международных отношений и мировых политических процессов, младший научный сотрудник международной междисциллинарной научно-исследовательской лаборатории изучения мировых и региональных социально-политических процессов Нижегородского государственного лингвистического университета им. Н.А. Добролюбова (603155, Россия, г. Нижний Новгород, ул. Минина, 31а); заместитель директора Приволжского филиала ФНИСЦ РАН (603000, Россия, г. Нижний Новгород, Холодный пер., 4; 4379037@gmail.com)

\title{
ВЛИЯНИЕ УСЛОВИЙ ТРУДА НА РОСТ НАПРЯЖЕННОСТИ В СОЦИАЛЬНО-ТРУДОВЫХ ОТНОШЕНИЯХ (на примере ПФО)
}

\begin{abstract}
Аннотация. В статье исследуются факторы, способствующие росту напряжений в сфере труда в Приволжском федеральном округе (ПФО). Процессы возникновения и усиления напряжений в сфере труда в ПФО анализируются на основании данных федеральной и региональной статистики. Неудовлетворенность условиями труда у работников рассматривается в качестве одного из ключевых факторов роста напряженности в трудовом коллективе. Авторы обосновывают идею, что предпринимаемые в настоящее время шаги по оптимизации напряжений, основанные на одностороннем видении ситуации сторонами трудовых отношений, нередко приобретают раздражающий характер и ведут к усилению напряжений в этой сфере.
\end{abstract}

Ключевые слова: сфера труда, трудовые отношения, напряжения в сфере труда, факторы напряжений, удовлетворенность работой, неформальная занятость, неполная занятость

A ктуальность и острота проблемы усиления напряжений в сфере труда связана с комплексом противоречий, возникающих в результате недовольства субъектов трудовых отношений, и перерастанием их в более широкую плоскость социальных взаимодействий. Это чревато в целом повышением 
конфликтности в регионе, снижением эффективности работы организаций и предприятий. Минимизация факторов и условий, стимулирующих напряжения, представляется крайне важной задачей для социально-политических институтов.

На наш взгляд, в основании напряжений в сфере труда находятся две группы факторов: во-первых, рассогласованность интересов участников трудовых отношений, во-вторых, неэффективность функционирования или зачастую отсутствие механизма разрешения противоречий между наемным работником и работодателем, несформированность модели оптимизации напряжений в сфере труда. Необходимо отметить, что эффективно функционирующие социальные институты (например, профсоюзы) способны своевременно и адекватно разрешать возникшие противоречия либо снижать их остроту.

Принципиальное значение имеют социологические методы и технологии, позволяющие оперативно выявить возникающие напряжения и установить их причины, динамику развития и специфические характеристики. В связи с этим представляется принципиально важным прогноз: «в ближайшие годы российская социология сможет более точно диагностировать состояние различных сфер жизни общества, находить точки напряжения и точки развития» 1 . Потребность в подобного рода социологическом инструментарии объясняется тем, что «социальная напряженность в ближайшие годы будет оказывать существенное влияние на экономику России» 2 .

Н.Е. Тихонова отмечает: «Кризисный период можно расценивать как переломную точку для формирования новых общественных ожиданий, в том числе и запросов к государству. Заметно его влияние в трудовой сфере - сюда относится не только ухудшение положения с зарплатой (характерное для более чем трети россиян - 37\%), но и общая ситуация на работе, ухудшение которой в разных формах затронуло четверть населения (26\%)» [Тихонова 2015]. K сожалению, необходимо констатировать, что реализуемые в настоящее время национальные проекты пока слабо влияют на ситуацию в сфере труда: в частности, в 2019 г. не были освоены 0,9 млрд руб., отведенных на нацпроект «Производительность труда и поддержка занятости», или $87 \% 3$.

Следует отметить, что противоречия, существующие в сфере труда современной России, не только регулярно проявляются в форме социальных напряжений и конфликтов, но и привлекают внимание на самом высоком государственном уровне. В связи с этим президент РФ В.В. Путин подчеркивает, что «ситуация на рынке труда все еще остается напряженной» ${ }^{4}$. Озабоченность высоким уровнем напряжений в социально-трудовых отношениях выражает и председатель Государственной думы РФ В.В. Володин ${ }^{5}$.

Сохраняющийся исследовательский интерес к явлению социального напряжения проявляется в поиске новых подходов, которые не обрели пока единого концептуального основания: «само понятие социальной напряженности отно-

\footnotetext{
1 Доклад о состоянии фундаментальных наук в Российской Федерации и о важнейших научных достижениях российских ученых в 2015 году. Утвержден решением общего собрания членов РАН 23 марта 2016 г. Москва. 2016. С. 136.

2 Доклад ВЭФ: социальная напряженность для РФ рискованней цен на нефть. 22.01.2013. Доступ: http://www.ria.ru/economy/20130122/919264425.html (проверено 12.05. 2021).

3 Агеева О. Кудрин упрекнул чиновников за непотраченные 1,1 трлн. - РБК. Доступ: https://www.rbc.ru/economics/20/02/2020/5e4bf90a9a7947c2b3d1074f (проверено 12.05.2021).

4 Совещание по экономическим вопросам при Президенте РФ. Доступ: http://kremlin. ru/events/president/news/64020 (проверено 12.05.2021).

5 Вячеслав Володин направил приветствие организаторам иучастникам IVMеждународной научно-практической конференции «Социально-трудовые конфликты в России и в мире». 30.03.2018. Доступ: http://duma.gov.ru/news/26603 (проверено 12.05.2021).
} 
сится не к отдельному индивиду, а к достаточно широким пластам общества» [Гаврилец, Клименко, Кудров 2016], «социально-экономические проблемы лишь одна из основных причин роста социальной напряженности» [Ivanov, Nazarov, Kublitskaya 2017].

Мы, в свою очередь, рассматриваем социальное напряжение как проявление неудовлетворенности, возникающей в виде субъектно-объектного отношения и содержащей латентную возможность трансформации в субъект-субъектное отношение. Возникающая под влиянием внешних условий неудовлетворенность представляет собой социальный феномен, в пространстве которого происходит трансформация объективного противоречия в процесс его осознания социальными субъектами, результатом чего выступает обнаружение причинно-следственной связи между характеристиками объекта неудовлетворенности и деятельностью других социальных субъектов. Осознание социальным субъектом сущности отношений в пространстве социального недовольства ведет к становлению и уточнению его «контрсубъекта» и возникновению напряжения между ними.

Социологические исследования в ряде случаев рассматриваются как основной источник информации о предпосылках, возникновении, динамике развития, специфике напряжений в области социально-трудовых отношений. Вместе с тем необходимо учитывать, что зачастую имеющиеся результаты социологических исследований не позволяют представить целостную картину состояния сферы труда в ПФО и практически несопоставимы между собой. В качестве основного источника информации мы использовали материалы федеральной и региональной статистики, позволяющие рассмотреть проблему как в статике, так и в динамике. Системное использование данных статистики позволяет не только выявить и описать процессы, протекающие в сфере труда, но и зафиксировать факторы, определяющие процессы возникновения и усиления напряжений в сфере труда различных субъектов ПФО.

На наш взгляд, систему трудовых отношений описывает комплекс статистических индикаторов и показателей. В представленной работе авторы обращаются к статистическим данным, позволяющим охарактеризовать условия усиления напряжений внутри системы социально-трудовых отношений. К таковым показателям, на наш взгляд, можно отнести:

- степень удовлетворенности сотрудников работой;

- доля занятых с низким уровнем заработной платы;

- доля работающих, пребывающих в постоянном стрессе или испытывающих частое нервное напряжение;

- доля рабочих, подвергающихся воздействию вредных веществ во время рабочего процесса;

- доля недовольных рабочим режимом;

- доля неформального сектора в общей занятости.

На наш взгляд, одним из важных факторов, определяющих уровень напряжения внутри сферы труда, является неудовлетворенность работников различными сторонами своего работы. Явными регионами-«лидерами» в 2018 г. по уровню неудовлетворенности сотрудников отдельными сторонами работы являлись Чувашская Республика (38,6\%), Саратовская обл. $(38,4 \%)$, Кировская обл. (36,5\%), Республика Марий Эл $(35,9 \%)$, Республика Башкортостан $(35,4 \%)$. Чуть лучше в этом отношении дела обстоят в Оренбургской обл. $(29,1 \%)$, Республике Татарстан $(27,7 \%)$ и Самарской обл. (22,9\%) (см. табл. 1).

Во всех субъектах ПФО основным фактором неудовлетворенности работой выступает заработок. Из приведенных в табл. 1 данных видно, что доля недовольных уровнем заработной платы в регионах ПФО весьма высока и 
составляет в среднем 60-70\%. Особенно заметно это в Республике Марий Эл, Кировской обл. и Чувашской Республике, где доля недовольных уровнем заработной платы составляет более $70 \%$. Наиболее благополучно в этом плане обстоят дела в Республике Татарстан $(49,2 \%)$, что коррелируется со средним показателем неудовлетворенности работников.

Результаты ранжирования субъектов ПФО по показателю неудовлетворенности отдельными сторонами работы представлены в табл. 1.

Таблица 1

Неудовлетворенность отдельными сторонами работы в субъектах ПФО*, \%

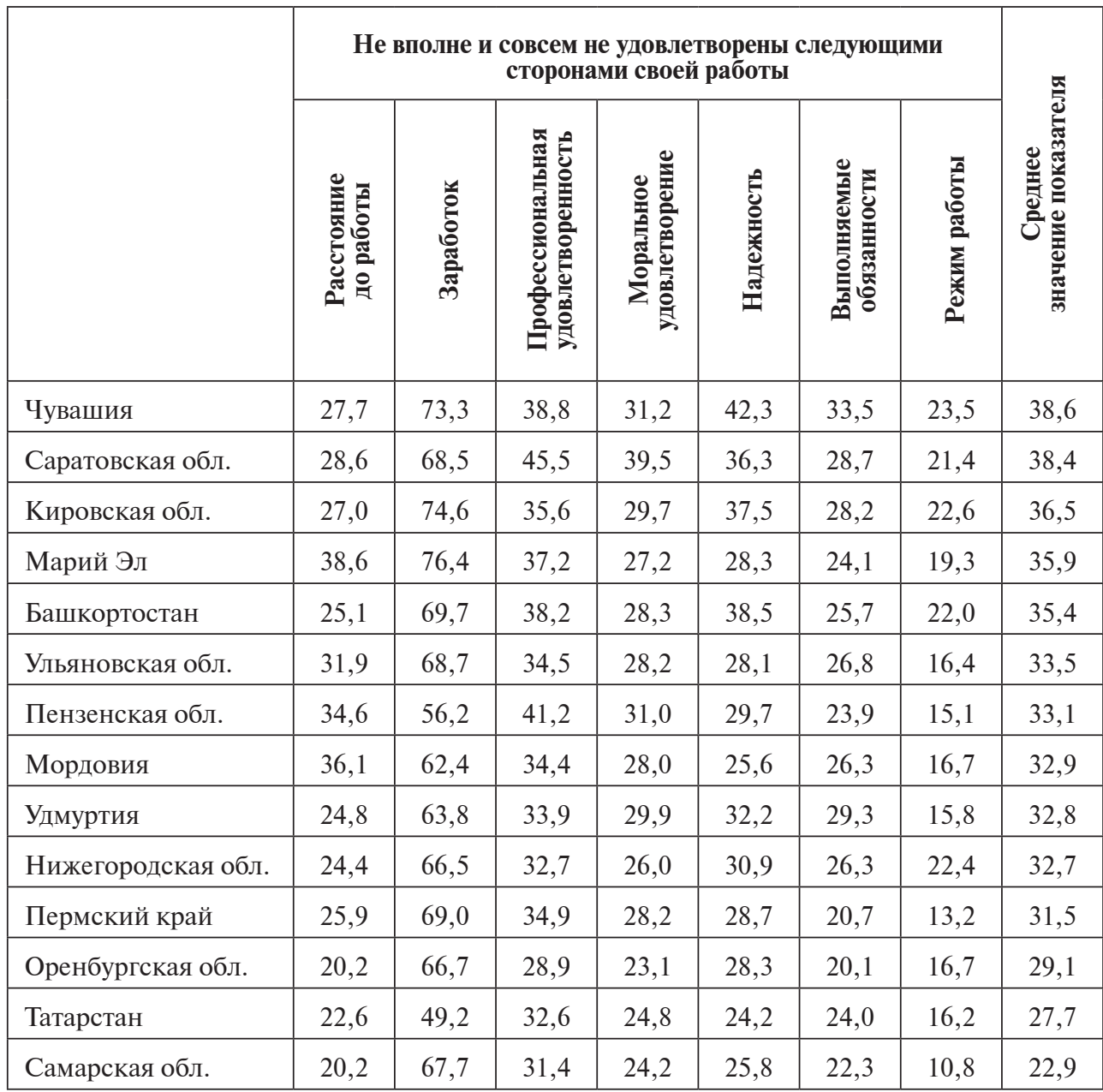

* Федеральная служба государственной статистики. Комплексное наблюдение условий жизни населения. Удовлетворенность работой. Доступ: https://gks.ru/free_doc/new_site/ KOUZ18/index.html (проверено 17.09.2020).

Анализ процесса изменения размера реальной среднемесячной начисленной заработной платы и динамики этого показателя в 2018-2020 гг. свидетельствует о волнообразном характере этого процесса, который сопровождается выраженными повышательными флуктуациями в конце года. Причем в первой 
половине года обычно наблюдается некоторое повышение, которое к концу года возвращается на прежний уровень ${ }^{1}$. Нестабильность размера реальной зарплаты позволяет предположить не только наличие элементов произвола при ее начислении, но и отсутствие надлежащего контроля со стороны государственных органов и профсоюзов.

В последние годы доля оплаты труда в структуре денежных доходов населения ПФО колебалась в пределах от $33 \%$ до $37 \%$ (см. табл. 2).

Таблица 2

Оплата труда в структуре денежных доходов населения ПФО*, \%

\begin{tabular}{|l|c|c|c|c|c|}
\hline \multicolumn{1}{|c|}{ Субъекты ПФО } & $\mathbf{2 0 1 3}$ & $\mathbf{2 0 1 4}$ & $\mathbf{2 0 1 5}$ & $\mathbf{2 0 1 6}$ & $\mathbf{2 0 1 7}$ \\
\hline ПФО & 36,9 & 35,9 & 33,3 & 35,3 & 37,1 \\
\hline \multicolumn{5}{|c|}{ Республики ПФО } \\
\hline Башкортостан & 29,7 & 30,1 & 28,5 & 29,8 & 31,2 \\
\hline Марий Эл & 41,6 & 40,6 & 37,6 & 37,8 & 39,0 \\
\hline Мордовия & 43,2 & 42,0 & 39,2 & 41,6 & 42,4 \\
\hline Татарстан & 36,9 & 35,4 & 33,1 & 33,3 & 35,8 \\
\hline Удмуртия & 41,9 & 40,7 & 36,6 & 39,5 & 42,2 \\
\hline Чувашия & 39,9 & 38,5 & 35,3 & 36,4 & 37,9 \\
\hline Пермский край & 34,1 & 33,8 & 30,3 & 34,6 & 37,8 \\
\hline & \multicolumn{2}{|c|}{ Области ПФО } & & \\
\hline Кировская & 40,1 & 38,4 & 36,1 & 38,4 & 38,9 \\
\hline Нижегородская & 38,9 & 36,7 & 33,2 & 35,1 & 37,8 \\
\hline Оренбургская & 42,7 & 40,9 & 38,5 & 42,1 & 41,5 \\
\hline Пензенская & 37,1 & 36,5 & 33,9 & 38,1 & 38,4 \\
\hline Самарская & 33,2 & 37,3 & 35,8 & 37,6 & 39,9 \\
\hline Саратовская & 39,0 & 37,6 & 33,1 & 35,3 & 36,6 \\
\hline Ульяновская & 35,0 & 32,6 & 32,2 & 33,8 & 34,8 \\
\hline
\end{tabular}

* Регионы России. Социально-экономические показатели. 2018: статистический сборник. М.: Росстат. 2018. С. 214.

Данные, представленные в табл. 2, свидетельствуют о заметных различиях по этому показателю между субъектами ПФО. Наибольшую долю оплата труда составляет в структуре денежных доходов населения Мордовии $(42,4 \%)$, Удмуртии $(42,2 \%)$, Оренбургской обл. $(41,5 \%)$ и заметно меньшую - в Башкортостане $(31,2 \%)$ и в Ульяновской обл. $(34,8 \%)$. Причем в большинстве

1 Федеральная служба государственной статистики. Социально-экономическое положение России. № 5. Январь-май 2020 г. С. 190. Доступ: https://www.gks.ru/storage/ mediabank/4xzzJeDk/osn-05-2020.pdf (проверено 17.09.2020). 
субъектов ПФО доля зарплаты в структуре доходов составляет немногим более трети.

Статистические данные свидетельствуют о сохранении в течение длительного времени просроченной задолженности по заработной плате, что убедительно свидетельствует о размывании социальной ответственности государства и предпринимательства. Структура общего объема задолженности из-за бюджетного недофинансирования выглядит следующим образом: на федеральный бюджет приходится $3,1 \%$, на региональные бюджеты $-89,9 \%$, и на местные бюджеты - 7,0\%. Задолженность по заработной плате из-за отсутствия собственных средств организаций на 1 июня 2020 г. составила 2409 млн руб., или $99,7 \%$ общего объема просроченной задолженности по заработной плате ${ }^{1}$.

Второе место по степени влияния на неудовлетворенность работой в большинстве субъектов ПФО занимает уровень профессиональной удовлетворенности. Исключение составляют республики Мордовия и Чувашия, в которых на второе место вышел такой фактор, как расстояние до работы. Данные статистики свидетельствуют, что удовлетворенность работой оказалась меньше всего связана с режимом работы.

На одном из последних мест среди факторов, определяющих уровень неудовлетворенности работой, в большинстве субъектов ПФО оказались «выполняемые обязанности». На наш взгляд, этот факт объясняется наличием специальности и степенью ее соответствия выполняемой работе. В 2018 г. выполняли основную работу, полностью соответствующую или близкую к полученной специальности, более половины работников в ПФО. Причем сравнительно более высока доля таких работников в Республике Татарстан (68\%) и в Самарской обл. (67\%). Доля работников, выполняющих основную работу, не соответствующую полученной специальности, сравнительно более высока в Чувашской Республике (45\%), а также в Саратовской (43\%) и Ульяновской обл. $(42 \%)^{2}$.

Важным фактором напряжений в сфере труда является оценка работниками условий труда. Следует отметить, что практически каждый пятый работник в России $(21 \%)$ оценивает свою работу как тяжелую и очень тяжелую. В субъектах ПФО значения этого показателя существенно различаются: от $30 \%$ в Республике Башкортостан до $10 \%$ в Ульяновской обл. Этот показатель также высок в Чувашской Республике (30\%), Пензенской обл. (30\%), в Республике Мордовия $(28 \%)^{3}$.

Обращает на себя внимание тот факт, что весьма высока доля работников, находящихся в стрессовом состоянии или испытывающих постоянное нервное напряжение на работе. В соответствии со статистическими данными, почти каждый четвертый работник в Саратовской обл. $(25,3 \%)$, Чувашской Республике $(25,6 \%)$ и Республике Марий Эл $(27,6 \%)$ находятся в таком состоянии. Самый низкий показатель зафиксирован в Самарской обл. $(12,2 \%)$ (см. табл. 3).

Постоянно испытывают на работе воздействие вредных производственных факторов значительная часть работников в республиках Марий Эл $(29,8 \%)$, Чувашия $(30,2 \%)$, в Кировской обл. $(29,1 \%)$. Значительно ниже этот показатель в республиках Мордовия $(16,8 \%)$ и Татарстан $(17,5 \%)$, в Нижегородской $(17,1 \%)$, Пензенской $(15,6 \%)$, Самарской $(17,6 \%)$ обл. (см. табл. 3$)$.

1 Там же.

2 Федеральная служба государственной статистики. Комплексное наблюдение условий жизни населения. Субъекты РФ. Доступ: https://gks.ru/free_doc/new_site/KOUZ18/index. html (проверено 17.09.2020).

3 Там же. 
Таблица 3

Доля работников в субъектах ПФО, испытывающих на работе воздействие вредных производственных факторов ${ }^{*} \%$

\begin{tabular}{|c|c|c|c|c|c|c|}
\hline \multirow[b]{3}{*}{ Субъект ПФО } & \multicolumn{6}{|c|}{$\begin{array}{c}\text { Доля работников, которые указали, что испытывают } \\
\text { на своей основной работе } \\
\end{array}$} \\
\hline & \multicolumn{3}{|c|}{ постоянно } & \multicolumn{3}{|c|}{ иногда } \\
\hline & 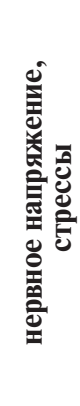 & 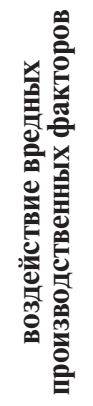 & 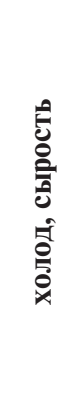 & 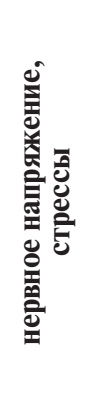 & 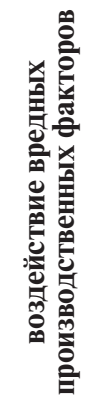 & 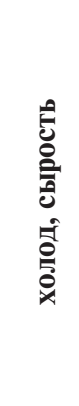 \\
\hline \multicolumn{7}{|c|}{ Республики ПФО } \\
\hline Башкортостан & 20,9 & 21,8 & 15,9 & 54,2 & 32,7 & 34,2 \\
\hline Марий Эл & 27,6 & 29,8 & 19,0 & 40,3 & 29,2 & 39,3 \\
\hline Мордовия & 23,1 & 16,8 & 8,6 & 38,8 & 23,5 & 25,8 \\
\hline Татарстан & 17,9 & 17,5 & 13,0 & 49,1 & 26,0 & 30,1 \\
\hline Удмуртия & 21,1 & 25,4 & 11,0 & 56,3 & 30,6 & 32,1 \\
\hline Чувашия & 25,6 & 30,2 & 18,4 & 51,0 & 17,7 & 28,9 \\
\hline Пермский край & 21,1 & 24,0 & 13,6 & 55,1 & 29,2 & 27,4 \\
\hline \multicolumn{7}{|c|}{ Области ПФО } \\
\hline Кировская & 24,0 & 29,1 & 22,3 & 52,1 & 26,1 & 33,2 \\
\hline Нижегородская & 20,2 & 17,1 & 13,2 & 55,1 & 30,9 & 26,6 \\
\hline Оренбургская & 18,0 & 22,7 & 11,8 & 38,0 & 28,7 & 30,5 \\
\hline Пензенская & 18,0 & 15,6 & 9,9 & 47,3 & 31,6 & 35,1 \\
\hline Самарская & 12,2 & 17,6 & 7,1 & 58,4 & 28,7 & 26,2 \\
\hline Саратовская & 25,3 & 22,9 & 18,4 & 51,3 & 33,7 & 33,7 \\
\hline Ульяновская & 21,2 & 20,4 & 11,2 & 48,1 & 30,5 & 33,2 \\
\hline
\end{tabular}

* Федеральная служба государственной статистики. Комплексное наблюдение условий жизни населения. Условия труда. Доступ: https://gks.ru/free_doc/new_site/KOUZ18/index. html (проверено 17.09. 2020).

Значительная часть работников в ПФО постоянно работают в неблагоприятных условиях, в т.ч. подвергаются воздействию холода, сырости. Сравнительно более высок этот показатель в республиках Марий Эл (19\%), Чувашия $(18,4 \%)$, а также в Кировской $(22,3 \%)$ и Саратовской $(18,4 \%)$ обл.

Необходимо отметить рост доли неформального сектора в общей занятости населения России на протяжении последних 10 лет. Так, Р.И. Анисимов отмечает, что «такое положение дел, а также слабость коллективных способов борьбы ведет к фактическому бесправию работников, наделяет неограничен- 
ной властью менеджмент организаций, унижает человеческое достоинство и воспроизводит трудовые отношения, характерные для “дикого капитализма”» [Анисимов 2017].

Предельно общим понятием неформальной занятости является «совокупность неформальных рабочих мест независимо от того, где они находятся» [Гимпельсон, Капелюшников 2014: 87]. По мнению Ж.Т. Тощенко, нужно различать неформальный сектор экономики и неформальную занятость, которая существует и в формальной экономике [Тощенко 2018: 92]. Согласно официальным данным, доля неформального сектора в структуре занятости в России стала увеличиваться с начала рыночных реформ, особенно в XXI в. На протяжении последних 10 лет доля неформального сектора в общей занятости населения России увеличилась. Причем этот процесс более заметен среди мужчин: в 2018 г. доля мужчин, занятых в неформальном секторе экономики, составила $22 \%$ (см. табл. 4$)$.

Таблица 4

Доля неформального сектора в общей занятости населения РФ*, \%

\begin{tabular}{|l|c|c|c|c|c|c|c|c|c|c|}
\hline $\begin{array}{c}\text { Заняты в неформальном } \\
\text { секторе }\end{array}$ & $\mathbf{2 0 0 9}$ & $\mathbf{2 0 1 0}$ & $\mathbf{2 0 1 1}$ & $\mathbf{2 0 1 2}$ & $\mathbf{2 0 1 3}$ & $\mathbf{2 0 1 4}$ & $\mathbf{2 0 1 5}$ & $\mathbf{2 0 1 6}$ & $\mathbf{2 0 1 7}$ & $\mathbf{2 0 1 8}$ \\
\hline Всего & 19,3 & 16,4 & 18,2 & 19,0 & 19,7 & 20,1 & 20,5 & 21,2 & 19,8 & 20,1 \\
\hline Мужчины & 20,5 & 18,1 & 19,6 & 20,4 & 21,2 & 21,7 & 22,2 & 22,9 & 21,5 & 21,7 \\
\hline Женщины & 18,0 & 14,7 & 16,8 & 17,6 & 18,2 & 18,5 & 18,7 & 19,4 & 18,0 & 18,4 \\
\hline
\end{tabular}

* Федеральная служба государственной статистики. Рынок труда, занятость и заработная плата. Индикаторы достойного труда. Доступ: https://www.gks.ru/labor_market_ employment_salaries (проверено 17.09.2020).

Неформальная и неполная занятость существенно затрудняют выстраивание стратегий выживания заметной части занятого населения ПФО. Среди субъектов ПФО доля неполной занятости в большей степени наблюдается в Чувашии $(11,3 \%)$, Мордовии $(10,8 \%)$, Удмуртии $(10,3 \%)$ и Кировской обл. $(10,2 \%)$. Наименьший показатель - в Саратовской $(2,5 \%)$ и Самарской $(3,4 \%)$ обл. ${ }^{1}$

Таким образом, представленные показатели свидетельствуют о перегрузке и избыточности проблем и противоречий на рынке труда в регионах ПФО. На сегодняшний день работники оказываются в сложной ситуации, когда ухудшение условий труда происходит в контексте нарастания неопределенности трудовых отношений, что позволяет увеличивать давление на них со стороны работодателя и усиливать их эксплуатацию.

Мы солидарны с выводом, что «социально-психологическое состояние россиян и оценка ими динамики материального положения - как наблюдаемого, так и ожидаемого - свидетельствуют, что они терпимы к экономическим изменениям. Однако это скорее результат “привыкания” и традиционных способов адаптации, нежели итог активизации и имплементации эффективных стратегий, связанных с развитием человеческого капитала, активными действиями на рынке труда, которые позволили бы заложить социальную базу для дальнейшего устойчивого развития страны» [Мареева 2017].

Работодатели привыкли, что сотрудники им полностью подконтрольны, однако обостряющиеся противоречия между хозяевами компаний и наемным

\footnotetext{
1 Федеральная служба государственной статистики. Рынок труда, занятость и заработная плата. Доступ: https://showdata.gks.ru/finder/descriptors/277278 (проверено 17.09.2020).
} 
персоналом могут привести и уже приводят к усилению напряжений между ними: по меньшей мере «каждый пятый россиянин $(22 \%)$ считает, что противоречия между собственниками и наемными сотрудниками предприятий для России - одни из самых серьезных. В общем рейтинге этот пункт занимает четвертое место после конфликтов богатых и бедных, власти и народа, чиновников и граждан» 1 .

Вызывает особую тревогу просроченная задолженность по заработной плате из-за несвоевременного получения денежных средств из бюджетов всех уровней. Если само государство имеет просроченную задолженность по заработной плате, оно более снисходительно относится к подобным явлениям на предприятиях и в организациях, принадлежащих частному капиталу. С другой стороны, достаточно очевидно, что представители бизнеса, наблюдая такие явления в бюджетных организациях, неизбежно приходят к выводу об их допустимости.

Необходимо заметить, что обозначенные выше противоречия развиваются в условиях ярко выраженного «сотрудничества» бизнеса и власти, их консолидации в единый блок, что влияет на характер отношений работодателя и сотрудников. Работодатель занимает более жесткую позицию при обсуждении и решении наиболее значимых проблем, таких как заработная плата, условия труда и т.д. Вектор на кооперацию с властью приводит к тому, что в руках работодателя оказываются основные возможности по снижению противоречий в сфере труда, что приводит к деформации такого института, как профсоюз. В результате этого профсоюзы теряют доверие работников, т.к. фактически утрачивают способность выражать интересы трудового коллектива.

Следует подчеркнуть, что предпринимаемые сторонами шаги по оптимизации напряжений в социально-трудовой сфере, основанные на фрагментарном, одностороннем видении ситуации как представителями наемных работников, работодателями, так и представителями власти, нередко приобретают раздражающий, провоцирующий характер и нередко ведут к возникновению и усилению социальных напряжений. В настоящее время важно выявить и оценить деструктивный потенциал таких напряжений, способы их оптимизации и локализации. Используемые в настоящее время способы нередко оказываются не вполне адекватными, поскольку напряжения в сфере труда чаще всего являются многофакторными, а нередко и закрытыми от общества.

Определение путей оптимизации социальных напряжений в России предполагает решение вопросов стратегического характера и, прежде всего, избавления от крайностей «дикого капитализма», представляющего собой угрозу процессу становления органичного для России «солидарного общества», главным принципом которого является совместное стремление к общим целям, определенным на основании консенсуса большинства, с учетом частных интересов.

Подлинная оптимизация социального напряжения достигается исключительно при условии объективного, заинтересованного анализа противостоящими субъектами источников и содержания возникшего между ними противоречия. Успешный процесс оптимизации напряжений в сфере труда возможен только вследствие реального преодоления тех обстоятельств, которые породили напряжение, позволяющего установить отношения согласия, удовлетворяющие стороны трудовых отношений.

Оптимизация социальных напряжений предполагает уточнение социальных норм, адекватных процессам изменения социальной реальности. Следует

1 Добрынина Е. Рабочая полночь. Конфликт «новых капиталистов» и их наемных работников может в скором времени резко обостриться. - РГ. Федеральный выпуск. № 6869(1). 10.01.2016. Доступ: https://rg.ru/2016/01/11/rabota.html (проверено 12.05.2021). 
подчеркнуть, что речь не идет о том, чтобы выдумывать нормы для растерявшего их общества. В ситуации их разрушения жизненно необходимо не только аккумулировать нормы, бытующие в сфере труда, но и выявить, представить новые, только возникающие, поддерживая их становление в качестве социально признанных.

Следует подчеркнуть, что поведение сторон в пространстве социального напряжения не отделено от сложившейся в данном обществе традиции, тесно связано с существующими в нем ценностями и стереотипами поведения, совокупность которых, аккумулированная в стратегии оптимизации социального напряжения, выступает основным инструментом социального регулирования сферы труда.

\section{Список литературы}

Анисимов Р.И. 2017. Труд в эпоху неопределенности. - Социс. Социологические исследования. № 11. С. 44-52.

Гаврилец Ю.Н., Клименко К.В., Кудров А.В. 2016. Статистический анализ факторов социальной напряженности в России. - Экономика и математические методы. Т. 52. № 1. С. 45-66.

Гимпельсон В.Е., Капелюшников Р.И. 2014. В тени регулирования: неформальность на российском рынке труда: монография. М.: ИД ВШЭ. 536 с.

Мареева С.В. 2017. Адаптация россиян к последствиям экономического кризиса. - Социс. Социологические исследования. № 11. С. 65-75.

Тихонова Н.Е. 2015. Явные и неявные последствия экономических кризисов для россиян. - Социс. Социологические исследования. № 12. С. 16-27.

Тощенко Ж.Т. 2018 Прекариат: от протокласса к новому классу: монография. М.: Наука. 350 c.

Ivanov V.N., Nazarov M.M., Kublitskaya E.A. 2017. Social Tension versus the Social Situation. - Herald of Russian Academy of Sciences. Vol. 87. No. 5. P. 432-438.

KUKONKOV Pavel Ivanovich, Cand.Sci. (Soc.), Senior Researcher of the Volga Branch of the Federal Center of Theoretical and Applied Sociology, Russian Academy of Sciences (4 Holodny Lane, Nizhny Novgorod, Russia, 603000; kukonkov_pavel@rambler.ru)

USTINKIN Sergey Vasilyevich, Dr.Sci. (Hist.), Professor; Director of the Volga Branch of the Federal Center of Theoretical and Applied Sociology, Russian Academy of Sciences (4 Holodny Lane, Nizhny Novgorod, Russia, 603000; Head of the International Cross-Disciplinary Laboratory for Studies of Global and Regional Sociopolitical Processes; Scientific Director of the Higher School of International Relations and World Politics, Dobroljubov State Linguistics University of Nizhny Novgorod (31a Minina St, Nizhny Novgorod, Russia, 603155); sv.ustinkin@gmail.com)

MOROZOVA Natalia Mihailovna, Cand.Sci. (Pol.Sci), Associate Professor of the Department of International Relations and Global Political Processes, Junior Researcher of the International Cross-Disciplinary Laboratory for Studies of Global and Regional Sociopolitical Processes, Dobroljubov State Linguistics University of Nizhny Novgorod (31a Minina St, Nizhny Novgorod, Russia, 603155), Deputy Director of the Volga Branch of the Federal Center of Theoretical and Applied Sociology, Russian Academy of Sciences (4 Holodny Lane, Nizhny Novgorod, Russia, 603000; 4379037@gmail.com)

\section{INFLUENCE OF WORKING CONDITIONS ON GROWTH OF TENSION IN SOCIAL AND LABOR RELATIONS (on the example of the Volga Federal District)}


processes of the emergence and intensification of tensions in the labor sphere of the Volga Federal District are analyzed on the base of federal and regional statistics. Employee dissatisfaction with working conditions is one of the key factors in the growth of tensions in the work collective. The authors conclude that the current steps taken to ease the tensions based on a unilateral perspective on the situation by the parties to the labor relations often become irritating and lead to the escalation of tensions in this area.

Keywords: labor sphere, labor relations, tensions in the labor sphere, tension factors, work satisfaction, unreported employment, part-time work

ОЛЕЙНИК Светлана Анатольевна - соискатель кафедры социальных технологий и государственной службы Белгородского государственного национального исследовательского университета (308015, Россия, г. Белгород, ул. Победы, 85)

\title{
ОСОБЕННОСТИ ГОСУДАРСТВЕННОЙ ПОЛИТИКИ ИНТЕГРАЦИИ ИММИГРАНТОВ В ПРИГРАНИЧНЫХ РЕГИОНАХ
}

\begin{abstract}
Аннотация. В статье рассматриваются различные особенности реализации государственной миграционной политики в отношении мигрантов в приграничных регионах. Подчеркивается необходимость проведения политики, направленной на интеграцию мигрантов в принимающее сообщество. Автор делает вывод, что одной из ключевых задач государственной политики в данной области должна стать организация регулярного мониторинга миграционной среды приграничья на основе трех групп индикаторов: социально-психологических, этнокультурных и социально-экономических. Автор предлагает создать в приграничных регионах единую управляющую систему, в работу которой должны быть вовлечены все государственные и общественные субъекты, осуществляющие деятельность в области интеграции мигрантов.
\end{abstract}

Ключевые слова: миграционные процессы, интеграция мигрантов, приграничные регионы.

Мграционные процессы в сегодняшней геополитической реальности ока-
зывают существенное влияние на развитие всех государств без исключе-
ния. Повышается роль и значение приграничных регионов, так как размыва-
ется граница между внутренней и внешней политикой, растет международная
активность регионов и других объектов федеративных государств [Межевич
2006]. Это обусловливает необходимость выработки действенных механизмов
интеграции иммигрантов в принимающее сообщество с учетом максимальной
пользы для всех сторон данного процесса.
Интерес исследователей к изучению проблем интеграции мигрантов в при-
нимающее сообщество возрастает в геометрической прогрессии. Многие из
них сходятся в мнении, что иммиграция в ближайшие десятилетия может стать
единственным источником снижения уровня депопуляции [Бормотова 2020].
Вместе с тем ряд ученых в своих работах обращают внимание на негативные
стороны массовой миграции. По мнению В.И. Мукомеля, «массовый приток
полиэтничных мигрантов - ввиду сокращения миграционного потенциала
соотечественников - станет глобальным вызовом», если на достойном уровне
не обеспечить их интеграцию. Самым негативным сценарием может стать 